\title{
Marinetti y el modelo de artista moderno
}

\section{Marinetti and the model of the modern artist}

\author{
Clara Hernández \\ Universidad Complutense de Madrid. \\ clarahernandez.st@gmail.com
}

Recibido: 23 de mayo de 2016

Aprobado: 14 de julio de 2016

\section{Resumen}

El objetivo de este artículo es analizar la figura del artista a comienzos del siglo XX a través de los textos y las ideas del poeta italiano Filippo Tommaso Marinetti. Partiendo sus teorías de las bases del decadentismo, Marinetti genera un modelo de artista en el que ejercen gran influencia conceptos como el genio y la libertad artística, muy asociados al Romanticismo, pero al que añade nuevos elementos de gran relevancia para la coyuntura política y social de su época. Entre estos, estarían aquellos que vincularon al artista futurista con la política de su tiempo, con el fascismo y con los modos de comunicación con el cada vez más importante público de grandes masas. Obsesionado con la idea de progreso, Marinetti aspira a crear un nuevo artista capaz de generar un nuevo mundo que introdujera definitivamente a Italia en la modernidad.

Palabras clave: Marinetti, Futurismo, Decadentismo, Fascismo, artista moderno.

Hernández, C. (2016): Marinetti y el modelo de artista moderno. Arte, Individuo y Sociedad, 28(3) 601621

\begin{abstract}
The aim of this paper is to analyze the figure of the artist at the beginning of the $20^{\text {th }}$ century trough the texts and the thought of the Italian poet Filippo Tomasso Marinetti. Based his ideas on the decadent movement, Marinetti creates a model of artist in which the concepts of genius and artistic freedom, linked to Romanticism, have a great influence. Bur he also adds new elements with a strong relevance for the social and politic circumstances. Among them, they were those that connected the futurist artist to the politic of his time, to the fascism and to the ways of communication with the big multitudes, that were getting increasingly important. Obsessed with the idea of progress, Marinetti aspired to create a new artist capable of generate a new world that inserted definitively Italy into the modernity.
\end{abstract}

Keywords: Marinetti, Futurism, Decadent movement, Fascism, modern artist. 
Sumario: 1. Introducción, 2. Romanticismo y sacerdotes laicos, 3. Dandismo y bohemia, 4. Decadentismo y vanguardia, 5. Marinetti y el artista futurista, 6. Progreso, nación y guerra: el artista futurista y la acción, 7. Conclusiones. Referencias. Notas.

Este artículo está financiado por el Ministerio de Economía y Competitividad en el marco del proyecto Educación artística en museos e instituciones culturales como recurso de bienestar para personas con Alzheimer y demencias tempranas. [EDU2013-43253-R].

\section{Introducción}

Cuando en febrero de 1909 Filippo Tommaso Marinetti publicó el Primer Manifiesto Futurista en el periódico francés Le Figaro, tenía como objetivo algo mucho más ambicioso que escandalizar a la opinión pública francesa y europea, cosa que consiguió a la perfección. El alboroto y la provocación eran herramientas que el joven poeta italiano estaba comenzando a utilizar como método de enorme eficacia para captar la atención del público y darse a conocer, tanto a él mismo como al movimiento que acababa de fundar. Su meta real era conseguir afianzar un movimiento artístico que englobara no solo todos los campos de las artes y de la literatura, sino que fuera en sí mismo una manera de entender el mundo. Es decir, Marinetti aspiraba a crear una nueva cosmovisión basada y originada por preceptos artísticos. Y por ello, el futurismo fundado por Marinetti fue un movimiento tanto artístico como extra artístico.

Para Marinetti, esta cosmovisión era su ideal de modernidad, concepto clave en los debates de la época y que fue para Marinetti el centro de su ideología y el objetivo de su actividad. Para lograr alcanzarla, debía producirse un cambio global que afectara a cada elemento de la sociedad y cultura habida hasta entonces. Debía destruirse todo lo anterior y construir un mundo nuevo, y en esa nueva composición del universo el arte debía ser la base sobre la que asentar los nuevos elementos, un arte por supuesto futurista, ya que este encarnaba el ideal de modernidad.

Futurismo y modernidad estaban indisociablemente unidos, y por ello el artista futurista era la personificación de la modernidad. Marinetti entendía el arte como vehículo para la modernidad pero también como máxima representación de esta, es decir, era tanto medio como fin.

Además, en esta concepción artística y extra artística, Marinetti no separaba los elementos que consideraba que componían la modernidad del mismo concepto del arte, siendo esta fusión elemento clave del futurismo. Entre estos estarían conceptos tan de moda en su época como el progreso, la nación, la vitalidad o el heroísmo. Para Marinetti, estos elementos de la vida moderna eran considerados artísticos dentro de su concepción futurista del mundo y por ello un coche de carreras resultaba más bello que la victoria de Samotracia.

El rol del artista sería entonces crucial para recomponer la sociedad y hacerla moderna y futurista. El nuevo artista, el artista futurista y por lo tanto realmente moderno era el que había sabido ver y reconocer la belleza y la sublimidad de la modernidad y el que había sido capaz de reunir todos los elementos de la vida moderna en un solo movimiento, viendo en estos el verdadero arte y en el arte la esencia de la modernidad. 
Así, en la mentalidad de Marinetti, futurismo era sinónimo de modernidad, y el artista futurista la encarnación de esta, por lo que debía tener la máxima libertad creadora. Siguiendo el modelo de artista romántico del decadentismo, este sería un artista genio que mostrara a la sociedad un nuevo mundo, en este caso ideado por él mismo (y no al servicio de unas ideas ajenas); es decir, ponía a la sociedad al servicio del arte, y no al revés. Lo que diferenciaba a Marinetti de los decadentistas es que Marinetti hacía del artista un elemento social activo y público. Se alejaba del modelo lánguido y apartado de la sociedad del decadente para hacer un actor del mundo en el que vivía, y que cambiaba a través de su arte.

Sin embargo, Marinetti renunciará a esta libertad suprema a la hora de elegir entre esta y la nación, que, si bien había tenido una importancia crucial en su ideología, ahora se impondrá sobre el resto de conceptos asociados a la modernidad. A partir de la I Guerra Mundial, la palabra libertad ya no será el término fundamental de su discurso, sino que quedará supeditada a la palabra Italia.

Siguiendo este camino, Marinetti irá primando cada vez más el elemento nacionalista y político del futurismo hasta colocar a este movimiento bajo el manto del fascismo. A pesar de este cambio, Marinetti continúa asociando al artista como guía de la modernidad y al arte como elemento que aúna en sí mismo todo aquello que él entiende como moderno, aunque ahora esto implique la preponderancia del elemento nacionalista.

El pensamiento de Marinetti se inscribe dentro de la cultura y la mentalidad europea de principios del siglo XX, y en este se pueden observar muchas de las aspiraciones y de los temores de una sociedad que se veía inmersa en un periodo de grandes y rápidos cambios. Pero Marinetti no es solo el reflejo de una época, sino un elemento activo de la misma, que tanto se ve influido por esta como influye en ella. Así, Marinetti, como típico personaje de la Belle Époque, fue capaz de utilizar las herramientas conceptuales, artísticas y culturales que su época le ofreció para generar un nuevo movimiento artístico y cultural, que marcó no solo al desarrollo del arte de vanguardias, sino, y dado su carácter global, a los propios modos de comportamiento ante el público y en la política.

Las ideas de Marinetti sobre cómo debía ser el artista moderno y cuál su papel en la sociedad tenían como origen en gran parte las ideas del decadentismo, movimiento al que él mismo perteneció durante sus primeros años de producción literaria. Aunque el resultado de sus planteamientos artísticos y literarios fueran muy distintos al decadentismo, tanto en forma como en contenido, la influencia de este en el futurismo es fundamental, sobre todo en algunos conceptos clave que afectan a la concepción misma del arte y del artista.

El futurismo tenía como base la idea de que el arte conforma un todo indisociable con la vida, en un sentido tanto cotidiano como espiritual, haciendo del futurismo el movimiento artístico y extra artístico que hoy conocemos. Para el futurismo, el hecho de que el arte afectara a cualquier aspecto de la vida del individuo moderno, que rebasara su propio término ampliándose hasta lo indefinido e indefinible, y que fuera el rasgo identitario de la sociedad moderna, colocaba al artista moderno en una posición de gran relevancia con un rol decisivo en la configuración de la sociedad y la cultura modernas. 


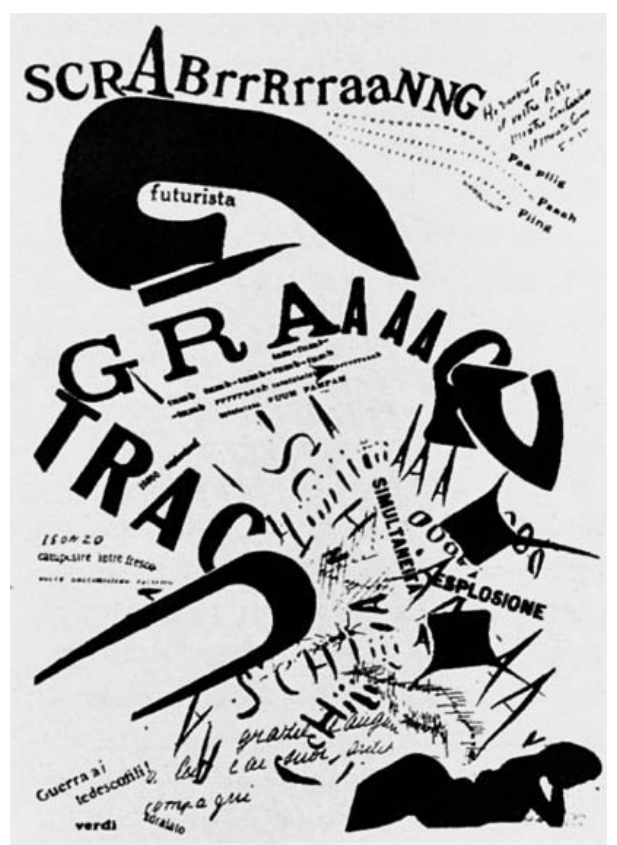

Figura 1. Marinetti, Tavola parolibera, 1917. Fuente: www.internetculturale.it

\section{Romanticismo y sacerdotes laicos}

Aunque es a finales del XIX cuando este concepto de lo artístico y lo estético como elemento que sobrepasa sus tradicionales límites para afectar de manera global la vida del individuo obtiene una gran repercusión y es su momento de mayor trascendencia de todo el siglo, principios de esta filosofía estética se sitúan entre los puntos fundamentales del Romanticismo, entendido por el historiador Renato Poggioli como movimiento precisamente por esta característica:

Romanticismo es término que trasciende los confines de la literatura y del arte y se extiende a todas las esferas de la vida cultural y civil [...] esta ilimitación va más allá del arte, esta aspiración a lo que los alemanes llaman una Weltanschaunng, es tal vez el principal carácter que diferencia aquellos que se llaman movimientos de lo que se llama escuelas. (Poggioli, 1964, p. 33).

Esta cualidad del Romanticismo de superar los márgenes tradicionales asociados a la labor artística y literaria supone un cambio a nivel conceptual y social tanto para la idea de arte como para la figura del artista. A partir del Romanticismo, el arte adquiere una relevancia cada vez mayor en el terreno intelectual dado que va tomando atribuciones anteriormente asociadas a otros campos, como son la filosofía o la religión. Así, el arte, al igual que la literatura, representa cada vez más un elemento espiritual laico que irá desplazando los dominios de la religión en su favor, mientras 
que la visión de los artistas y de los escritores tendrán cada vez más influencia en la manera de entender y de juzgar el mundo.

Este es uno de los rasgos del Romanticismo que más arraigarán en la cultura del XIX y que se será transmitido a la del XX, convirtiéndose en un concepto clave de la mentalidad moderna. El proceso tiene sus raíces en la Ilustración, como explica el historiador Tim Blanning: si el siglo XVIII había sido el siglo de la razón y de las certezas, también lo fue de una cada vez mayor pérdida de influencia de la religión y sus representantes en la sociedad y en la cultura. Así, cada vez más europeos educados encontraban insuficientes las doctrinas e instituciones tradicionales, y buscaron en el arte y en todas sus formas la vía para llenar el trascendental espacio que se había abierto (Blanning, 2012). Es precisamente en este proceso cuando el arte va adquiriendo su significado moderno, de acuerdo a las nuevas aspiraciones y pretensiones de los artistas y pensadores.

Como explica Paul Bénichou en su ya clásica obra La coronación del escritor (1981), es concretamente la figura del poeta la que se impone como representante (o sacerdote) de este nuevo poder espiritual laico en el que el Arte ocupa el lugar más elevado. Este cambio de paradigma en el sistema de valores culturales de la sociedad occidental implica que, si hasta el momento el filósofo ilustrado se situaba por encima del poeta como depositario del entendimiento del mundo, a partir de ahora es el poeta el que se impone como figura de referencia, y no solo espiritual, sino también intelectual:

La filosofía de las luces había consagrado al Literato, pensador y publicista. El espiritualismo del siglo XIX consagra al Poeta. [...] Pero la antítesis del Poeta y del Filósofo no ha resistido al advenimiento de un espiritualismo más amplio, que, en lugar de oponer los dos tipos, y sin dejar de mantener el privilegio de la Poesía, absorbía el uno en el otro. El tipo dominante fue entonces el Poeta-Pensador: un inspirado, portador de luces modernas a la vez que de misterio, que mostraba a los hombres, mientras los acompañaba en su camino, un objeto distante y puro. (Bénichou, 1981, p. 436-437).

En resumen, "lo artístico ampliaba sus límites hasta lo ilimitado" (Calvo Serraller, 2013 , p. 117), haciendo del arte un nuevo elemento de la vida moderna cuyo papel como fundamento de nuevas formas de pensar y de entender el mundo, la sociedad y la cultura fue reivindicado y defendido por diferentes artistas, literatos y pensadores. 


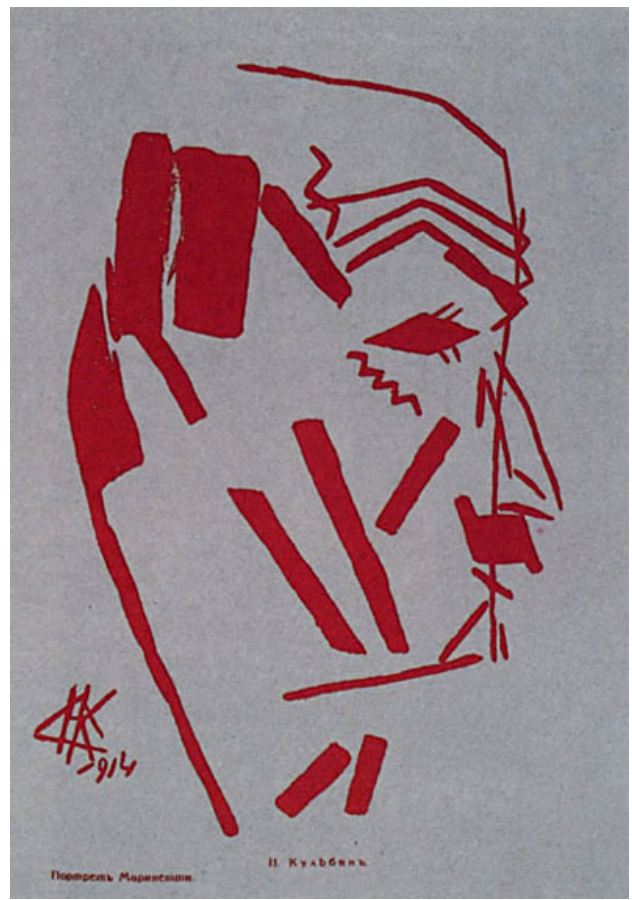

Figura 2. Nikolaj Kulbin, Ritratto di F.T. Marinetti, 1914. Fuente: www.internetculturale.it

\section{Dandismo y bohemia}

Comienza de esta forma a afianzarse nuevas formas de comportamiento y de conducta social partiendo de esta visión del mundo desde lo artístico y lo literario. Lo que a partir de mediados del siglo XIX se da como casos más marginales, irá poco a poco ampliándose e institucionalizándose como la forma "artística" de comportamiento de ciertos colectivos, siendo representativos de esta tendencia social la bohemia y el dandismo. Cada uno practicando un modo de vida distinto, con condiciones sociales y económicas diversas (por lo menos en teoría, dado que los primeros solían vivir al límite o en la pobreza y los segundos disfrutaban supuestamente de una saneada situación económica), ambos colectivos buscaban en el arte una forma de vida. El arte suponía la base sobre la ejercer la práctica social, estética y vital en general, sin importar (o quizá precisamente por ello) que implicara una oposición y un enfrentamiento hacia las convenciones sociales y morales del momento. Para ellos, el arte estaba por encima de estos aspectos y los bohemios y los dandis, cada uno desde su perspectiva, lo habían sabido ver y a ella se entregan, ya fuera viviendo malamente de su arte, ya fuera dedicando todo su esfuerzo y su sentido vital a ella.

El dandismo y la bohemia ejercieron una enorme influencia en la imagen del artista para los movimientos y tendencias artísticas posteriores, ya que se establecieron como paradigma del artista moderno siendo su forma de vida una parte fundamental de su filosofía y de su obra. 
Quienes la componen [la bohemia] son realmente aquellos a quienes llama el arte y tienen la suerte de ser además sus elegidos. Esta bohemia está también repleta de peligros, como las otras; la flanquean dos abismos: la miseria y la duda. (Murger, 2007, p. 26).

Todos [los dandis] participan del mismo carácter de oposición y de rebelión; todos son representantes de lo mejor que hay en el orgullo humano, de esa necesidad, demasiado escasa en los de hoy en día, de combatir y destruir la trivialidad. [...] El dandismo es el último destello de heroísmo en las decadencias. (Baudelaire, 2007, p. 116).

Estos modelos de comportamiento y de exploración artística y literaria a partir también de un modo de vida supondrá una importante aportación del Romanticismo a los fundamentos del arte moderno. El mismo Baudelaire, en uno de sus escritos del Salón de 1846, explica algunos de los puntos fundamentales del romanticismo, que vincula con esa nueva manera de sentir y de expresar a través del arte:

El romanticismo no está precisamente en la elección de los temas ni en la verdad exacta, sino en la manera de sentir. Han buscado fuera, y solo dentro era posible encontrarlo [...] Quien dice romanticismo dice arte moderno - es decir, intimidad, espiritualidad, color, aspiración al infinito, expresados por todos los medios que contienen las artes. (Baudelaire, 1999, p. 103-104).

Esa manera de estar, de entender, de enfrentarse y comunicarse con el mundo se relaciona con lo que este mismo autor explicaba como el heroísmo de la vida moderna en sus escritos del Salón del año anterior, un heroísmo que principalmente puede ser realizado por el artista moderno, ya que es él quien tiene la sensibilidad para comprender las realidades más profundas del hombre y su entorno (Baudelaire, 1999). Vinculando este heroísmo con la idea de genio, que vive en el romanticismo su máximo apogeo (Wittkower, 2004), se convierte al artista en el "héroe romántico por excelencia", ya que "nunca se había elevado tan alto como durante el romanticismo la consideración del genio artístico. Su propia naturaleza de genio le convierte ya en un rebelde: no sigue las normas de los otros, son los otros los que deben seguirle a él". (Aguirre, 1996, p. 5).

La influencia del pensamiento y del modo de vida de Baudelaire se hará especialmente profunda en el ambiente cultural de finales de siglo, marcando especialmente a los artistas y literatos del decadentismo. Para estos, Baudelaire encarna el perfecto caso de artista moderno, tanto por sus escritos como por su propia vida, por lo que su ejemplo actuará casi como arquetipo para los nuevos artistas y literatos.

La línea de pensamiento en relación al arte y a la vida propugnada por Baudelaire es asumida y asimilada por los decadentistas y simbolistas, quienes compartirán esa manera de entender el arte y esa "actitud vital y artística" (Herrero, 2012, p. 10) como fundamento para vivir de acuerdo a unos ideales contrarios a los establecidos.

Los decadentes alardearon de su gusto por lo sensible y por la belleza, entendida esta desde una perspectiva más profunda que el canon clásico y académico, y todo esto con una actitud de cierto corte aristocrático, puesto que en el mundo que ellos contemplaban, el arte era lo más elevado y eran solo ellos quienes lo habían comprendido y se habían entregado a ella. 
El gusto por lo exótico y lo perverso, el dandismo inmoral y elitista del decadentismo, parecieron una manifestación del degeneracionismo que se asoció con el fin de siglo; pero el esteticismo, la pasión por la belleza que lo inspiraba, eran [...] un ideal moral, una exaltación de lo sensible y lo bello contra la vulgaridad y el gusto convencionales. (Fusi, 2013, p. 108).

El mundo moderno, basado en filosofías positivistas y materialistas, no satisfacía las inquietudes internas de los artistas y los literatos decadentes, que buscaban a través de sus obras encontrarse con el aspecto espiritual y estético que el mundo físico no les brindaba. Estos artistas se rebelaban contra la sociedad burguesa en la que vivían (y a la que generalmente pertenecían) y sus modos de vida, contra un mundo fundamentado en ideas que no compartían y que consideraban vacías y mediocres, contra un mundo material y finito cuyos límites estaban marcados por esa lógica del positivismo.

La sensibilidad y las inquietudes de los jóvenes artistas y escritores no encuentran una respuesta ni un camino adecuados en las tendencias dominantes del pensamiento, de la literatura, del arte y de la moral social de la época. El conformismo, la mediocridad y la vulgaridad burgueses, el racionalismo y el materialismo reinantes, les parecen totalmente opuestos a la sensibilidad artística personal, al refinamiento auténticamente estético, gratuito y original, y a la sed de ideal y de infinito que perviven en el espíritu exigente e insaciable del hombre. (Herrero, 2012, p. 13)

Finaliza el siglo XIX con esta tendencia en la que la sensibilidad subjetiva es elemento ineludible y fundamental del pensamiento artístico moderno: desde ella se busca vivir de otra manera, con otros valores y otras ambiciones, y el espíritu de rebeldía, llevado por diferentes vías, será ya un elemento establecido y afianzado entre muchos de los jóvenes con aspiraciones artísticas y literarias al comenzar el nuevo siglo.

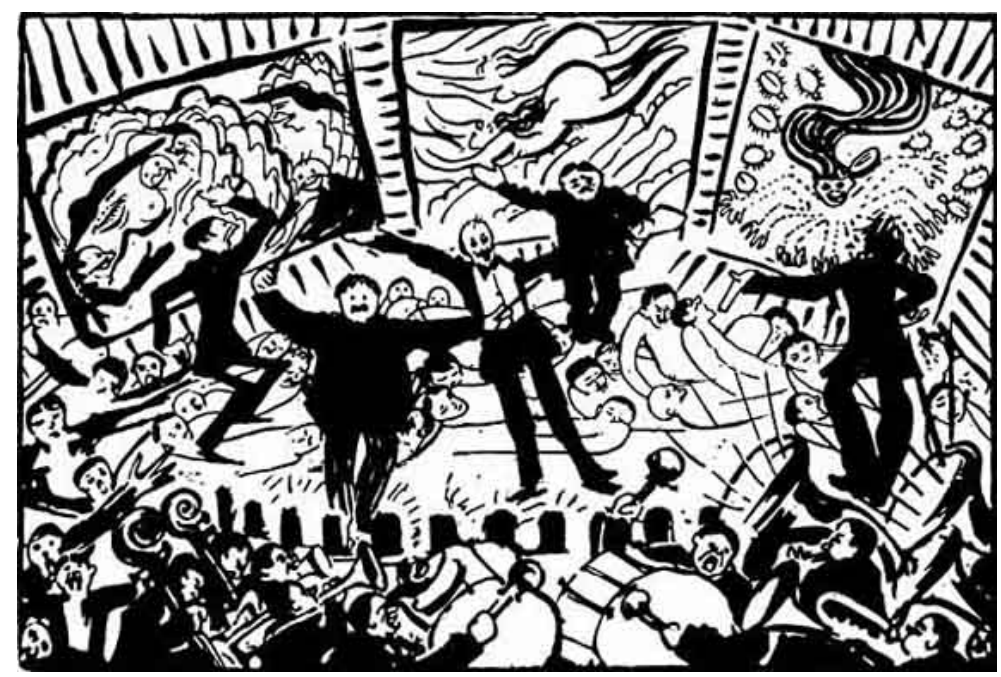

Figura 3. Umberto Boccioni, vignetta di una serata futurista, 1911. Fuente: www.internetculturale.it 


\section{Decadentismo y Vanguardia}

La relación entre una parte del pensamiento de vanguardia con el decadentismo y los modos de pensar y de actuar finiseculares hace que algunas ideas o comportamientos de gran relevancia de los artistas vanguardistas tengan una correspondencia con el pensamiento romántico (o por lo menos con el tardorromántico). Si esto podría aplicarse en general a las vanguardias de principios de siglo XX, el caso de Marinetti es quizá uno de los más claros en este aspecto. La imbricación del arte con la vida, que se ha visto en algunas de las principales tendencias y autores del Romanticismo, encuentra en Marinetti su más firme representante a comienzos del siglo XX, ya que, como se irá viendo, Marinetti funda el movimiento futurista precisamente con la intención de crear un nuevo modelo de sociedad basado en la correspondencia entre el arte y la vida.

La influencia del decadentismo en Marinetti es palpable tanto en muchas de sus ideas como en su modo de comportamiento, proviniendo esta del contacto directo que tuvo con este pensamiento por sus propios inicios literarios de Marinetti, quien comenzó su carrera artística escribiendo en un estilo de tendencia decadente y de corte simbolista. Si bien durante todo el resto de su vida criticó de manera furibunda a los decadentes y a los simbolistas sin miramiento alguno, y les dedicó importantes secciones de sus textos y de sus manifiestos, sus primeros poemas pertenecen a esa moda literaria. El hecho de que él mismo formara parte de ella genera también que, dadas sus lecturas y su estrecho contacto con esta literatura y con la cultura decimonónica, mantuviera, al menos al principio, algunas de sus ideas y de sus comportamientos como parte de su personalidad artística (aunque luego cambiara de estilo y de objetivos artísticos). Pero el que en inicio compartiera el gusto decadente de la época, también causó que el odio posterior a estas tendencias del XIX fuera aún más furibundo cuanto que él mismo formó parte de una de ellas. ${ }^{1}$

Así pues, la influencia decadentista sobre Marinetti es significativa, y Mario de Micheli (1993, p. 65) la destaca como un elemento de gran relevancia sobre él y sobre su obra: "En efecto, el padre del futurismo nace directamente de los lívidos lomos del decadentismo francés ruidosamente aliado al «superhombrismo» nietzscheano". ${ }^{2}$

Podemos ver elementos de gran importancia en el pensamiento de Marinetti que provienen directamente del decadentismo, y que se entremezclan con componentes nuevos y con un nuevo espíritu para formar una corriente diferente y futurista. El hecho de que el futurismo fuera una nueva vanguardia artística y vital y, sobre todo, que se proclamara como tal y como absolutamente rupturista con el pasado, no quiere decir que las fronteras y los límites de este movimiento y de sus contemporáneos fueran compactas, sino que eran permeables, que elementos de unos y de otros se traspasaban y la comunicación fluía, de una manera u otra, entre ellos.

Las mentalidades y las identidades se entrecruzaban a lo largo de generaciones creando individualidades fracturadas, amalgamas de distintos elementos, lo cual es, en sí mismo, parte integrante de la modernidad, notablemente exagerada por el carácter fragmentario del arte moderno y la filosofía. (Blom, 2010, p. 586). 
Así pues, Marinetti fue ese "decadente eufórico" (De Micheli, 1993, p. 63) de espíritu rompedor que con intención de crear una nueva praxis vital vanguardista creó un nuevo movimiento artístico con aspiraciones a la globalidad y a afectar a todas las esferas del hombre moderno.

Marinetti, como fundador del movimiento futurista ejerció esa "conducta de vanguardias" no solo como un acto de subversión destinado a escandalizar, provocar e incomodar a la sociedad burguesa del momento (Poggioli, 1964, p. 46 y De Micheli, 1993, p. 69) (que también), sino, como se ha comentado, como parte de su programa tanto artístico como vital futurista. Igual que los artistas del XIX, los vanguardistas buscaban, a través del arte, una nueva manera de vivir y de estar en el mundo, en la que el arte ocupara un lugar esencial en la configuración de su Weltanschaunng. Como explica Peter Bürger, los artistas de vanguardias seguían buscando, a través de otras vías y con nuevas ideas e ideales, otra praxis vital alternativa a la común:

Los vanguardistas no intentan en absoluto integrar el arte en esa praxis vital [burguesa]; por el contrario, comparten la recusación del mundo ordenado conforme a la racionalidad de los fines que había formulado el esteticismo. Lo que les distingue de éste es el intento de organizar, a partir del arte, una nueva praxis vital. También a este respecto el esteticismo es condición previa de la intervención vanguardista. Sólo un arte que se aparta completamente de la praxis vital (deteriorada), incluso por el contenido de sus obras, puede ser el eje sobre el que se pueda organizar una nueva praxis vital. (Bürger, 1997, p. 104).

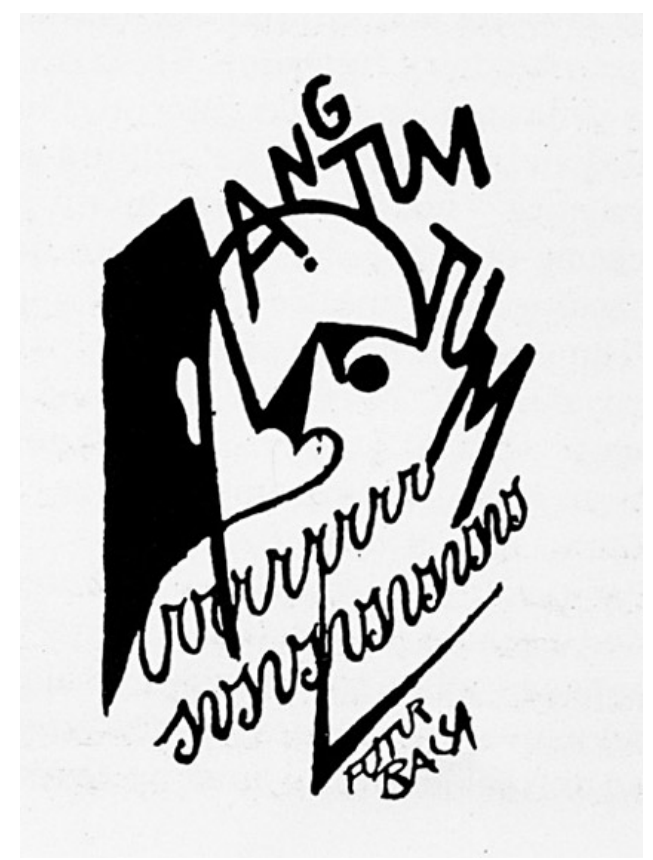

Figura 4. Giacomo Balla, Caricatura sintetica di Marinetti, 1924. Fuente: www.internetculturale.it 


\section{Marinetti y el artista futurista}

Una nueva praxis vital a partir del arte de vanguardia (del futurismo en su caso) es precisamente a lo que aspiraba Marinetti, y por ello el movimiento fundado por él trataba de alcanzar y de abarcar todos los aspectos tanto vitales y cotidianos como artísticos del individuo y de las masas. Su aspiración a la globalidad se correspondía con esa búsqueda de un movimiento total que fuera capaz de cambiar todos los aspectos de la vida del hombre para hacerlo verdaderamente moderno y adecuado al mundo que se presentaba a principios del siglo XX. Siguiendo con los parámetros románticos sobre el artista como sacerdote laico, para Marinetti era este el mejor capacitado para diseñar y construir el necesario y venidero mundo moderno, y para ello, el nuevo artista debía estar imbuido de los principios futuristas y de las ideas artísticas de este movimiento, que serán comentadas brevemente 3 .

El concepto de arte de Marinetti se basaba, ante todo, en la novedad, en lo rompedor, en lo original, llevado hasta el límite, hasta lo más radical y extremo. Para Marinetti el arte debía ser aquello que rompiera totalmente con lo establecido, con lo cotidiano, y que destruyera todo cuanto existiese para crear algo nuevo, y que, además, nunca pudiera establecerse de manera fija, porque de esa forma dejaría de ser la novedad. El arte sería así el primer paso de una revolución a nivel global que habría de cambiar todos los aspectos de la vida, pero también sería el último objetivo de este cambio; es decir, el arte se convertiría tanto en un medio como en un fin de esa radical transformación.

Por eso, el arte para este autor, y de acuerdo con su proyecto de destrucción de todo lo pasado, nunca debía estar basado en nada relacionado con lo hecho anteriormente. Así, algunos de sus puntos más famosos son aquellos en los que defiende la destrucción de los museos, de las bibliotecas, a los que denomina cementerios del $\operatorname{arte}^{3.1}$. Contra estos "santuarios" Marinetti proclama que es necesario escupir cada día en los altares del arte para entrar en los dominios ilimitados de la intuición libre ${ }^{3.2}$. También defendía la necesidad de acabar con la inmortalidad del arte, al comprender el valor de una obra artística únicamente en su momento, como algo vivo. Por ello, entendía que nunca debería ser transmitida más allá de la muerte de su autor, con quien debería desaparecer, porque si esta perviviera, se convertiría en un elemento de la tiranía passatista, su máximo enemigo ${ }^{3.3}$. El arte sería así vida y vitalidad, energía, movimiento, velocidad, es decir, el arte sería siempre sinónimo de los (ahora clásicos) conceptos fundamentales futuristas. El arte sinónimo de vida sería entendido como algo tan necesario y orgánico como extraordinario y elevado ${ }^{3.4}$, a la vez que como lucha y acción ${ }^{3-5}$.

Esta lucha constante, a su modo de ver, debía llegar hasta donde fuera necesario, siendo cada vez más radical y extrema, dado que siempre debe destruir lo preexistente. Marinetti utiliza el término "atentado artístico", como el punto al que sería preciso llegar si ni siquiera "las bofetadas y los puños" fueran suficientes para lograr los objetivos futuristas ${ }^{3.6}$. De esta forma, la originalidad, la renovación y la acción (incluida la violenta), serían las bases imprescindibles de esta nueva praxis vital y artística, opuestas radicalmente al arte antiguo (académico, repetitivo, copista, etc.), 
y sería lo que diferenciaría al nuevo artista del antiguo. Es decir, a modo de ver de Marinetti, el artista genial del ordinario, manteniendo la idea romántica del artista genio.

Así, la genialidad del artista sería punto clave de la imaginería futurista e iría unido al "valor absoluto de novedad"3.7. Para Marinetti, "nada podría imponerse a la genialidad del artista", ya que el genio artístico estaría por encima de todo y no debía obedecer a ninguna técnica, tradición o moral. ${ }^{3.8} \mathrm{El}$ artista debía ser libre para desarrollar todo su potencial y cambiar así el mundo según su voluntad, generando un nuevo universo que de esta forma sería realmente moderno, sin lastras del pasado. Los artistas podían y debían "descomponer y recomponer el Universo según sus maravillosos caprichos, para centuplicar la potencia del genio creador italiano y su predominio absoluto en el mundo". ${ }^{3.9}$

La imagen del artista futurista se correspondería, siguiendo muchos patrones del romanticismo, con el héroe. El artista, al hacer un arte vital, revolucionario en todos los sentidos, se convierte en un héroe de la modernidad que se sitúa por encima de todo y de todos los demás 3.10 .

En este punto, Marinetti, como se ha visto en otras ocasiones, toma elementos muy característicos del romanticismo mientras que rechaza categóricamente otros. Aquí, de nuevo, aborrece la languidez de sus predecesores y reniega de la imagen bohemia del artista, al que considera grotesco y sórdido, ${ }^{3.11}$. Y defiende este otro modelo de artista heroico, que combate y que lucha, tanto en el arte como en la vida, trasladando ese heroísmo a la vida cotidiana, una vida "necesariamente heroica" ${ }^{3.12}$

Su concepción del heroísmo moderno dista mucho de aquella idea de Baudelaire que tanta influencia tuvo en las generaciones posteriores, y aunque es más que probable que esta percepción del artista tuviera influencia en Marinetti, su concepción se encamina por vías completamente distintas, vinculadas con la acción política, la guerra y el nacionalismo.

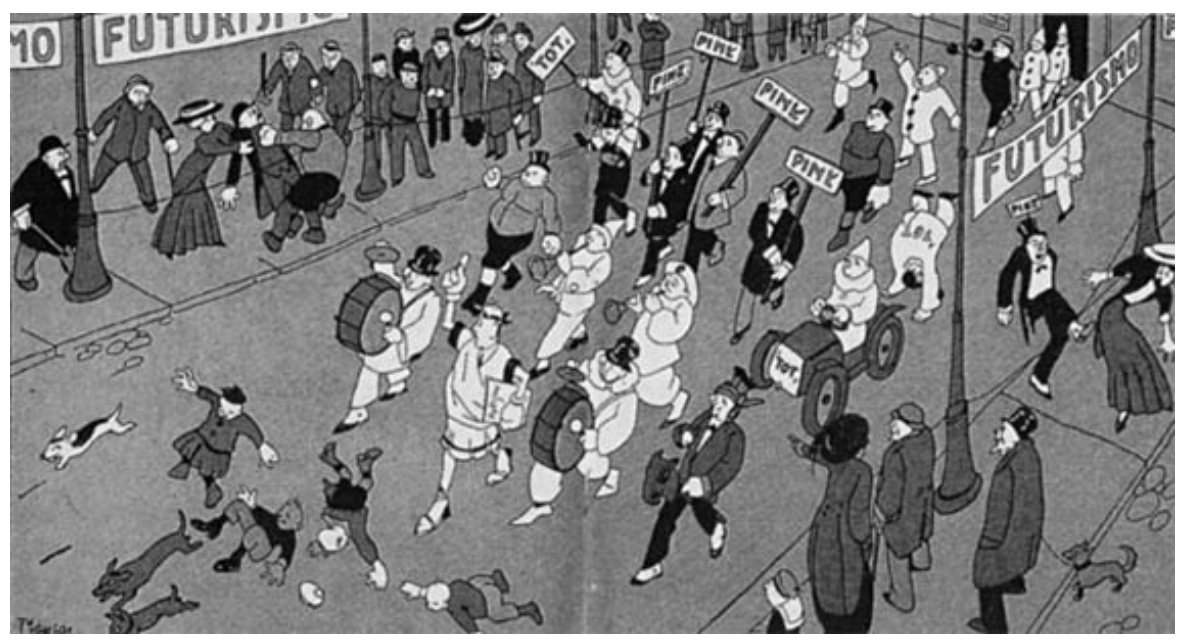

Figura 5. Giovanni Manca, vignetta, 1909. Fuente: www.internetculturale.it 


\section{Progreso, nación y guerra: el artista futurista y la acción}

El artista moderno y futurista no era para Marinetti, como se ha visto, un espectador del mundo, ni tampoco un mero cronista o un intérprete de su tiempo, sino que iba más allá de estas atribuciones y Marinetti lo convierte en un actuador, en un agente activo socialmente que participaba en su contexto para cambiarlo según su proyecto vital y artístico futurista.

Marinetti inserta al artista en la sociedad de su época, en la política y en la vida cotidiana de los ciudadanos, y su idea es hacerlo brusca y violentamente, no solo bajándolo de la torre de marfil de los decadentistas, ni tampoco haciéndolo mero representante o portavoz de una corriente ideológica o política, sino haciéndolo precisamente generador de corrientes que desbordaban los terrenos meramente artísticos para que llegaran a alcanzar también el terreno político.

Para Marinetti, la intervención en la política era algo natural para el artista futurista, ya que formaba parte de la acción y de la experiencia vital del mismo, por lo que no podía mantenerse al margen. Y pregonaba: "El futurismo proclama así la necesaria intervención de los artistas en las cosas públicas, para hacer finalmente del gobierno un arte desinteresado, en vez de esto que es ahora una pedantesca ciencia del robo". 3.13

Ahora bien, para Marinetti, como para muchos de sus contemporáneos, los límites entre los conceptos estéticos y políticos eran más que difusos. Partiendo de premisas estéticas elaboraban proclamas políticas, con insuflados discursos y aparatosas frases, pero sin un programa real o práctico. Siguiendo esto, y dentro de lo globalizante del futurismo como se ha comentado, Marinetti no separaba los conceptos artísticos, de los ideológicos ni de los políticos. Dentro de estos, se pueden distinguir tres puntos clave en torno a los que giraba su concepción política futurista, que son el progreso, la nación y la guerra. Estos eran entendidos por Marinetti como pilares fundamentales de la modernidad, y en ellos proyectaba sus ambiciones artísticas y extra artísticas, convirtiéndolos en una amalgama de ideas en las que primaba el componente estético, pero sin que esto implicara que no buscara un traslado a la realidad. Es decir, aunque Marinetti partía de concepciones estéticas para generar su ideario político e ideológico, buscaba, a través de la acción del futurismo y de los artistas futuristas, hacer realidad estas ideas, incluidas aquellas más radicales asociadas a la guerra, a la violencia o a la destrucción. Estas medidas eran, a su modo de ver, herramientas imprescindibles para lograr, como explica Emilio Gentile, que la revolución modernista del futurismo fuera cultural y moral, que transformara los valores, las ideas y las costumbres de los italianos, para crear el italiano nuevo de la modernidad (Gentile, 1988).

El progreso era inherente a la modernidad y además era representante de la oposición de Marinetti al decadentismo, por lo que tenía un carácter de desafío a la inactividad de sus maestros y antecesores intelectuales y artísticos, y representaba la nueva actitud artística y vital de la juventud italiana. Marinetti desarrolló una verdadera devoción por el progreso, al ser elemento irrefutable del discurso sobre la modernidad (Gómez Llanos, 2008), y dentro de su culto a este se incorporó elementos como el movimiento, la vida y la lucha, convirtiendo al progreso en la gran esperanza para la modernidad, por lo que entendía que siempre tendría la razón, incluso cuando 
fuera cruel $^{3.14}$. El progreso era la máquina y la velocidad, era Milán, la industria y las fábricas, eran los automóviles y la aviación. El progreso técnico demostraba la fortaleza de una nación, tanto a nivel cultural como, por supuesto, militar. Por ello, una nación moderna debía estar bajo las órdenes del progreso, de la acción y de la vitalidad, y el artista debía perseguirlo e incorporarlo a su obra, tanto a la forma como al contenido, buscando siempre la novedad y despojándose de toda influencia del pasado.

La nación era entendida por Marinetti, como por muchos de sus contemporáneos, como una categoría más estética que política, que tenía como origen la filosofía del Romanticismo nacionalista pero que a partir de finales del siglo XIX sufrió un proceso de radicalización que la situó como esencia de la identidad de los individuos, unidos a su patria orgánicamente por lazos raciales y culturales que les generaban sentimientos de cohesión con su pueblo (Fusi, 2003).

Este es uno de los aspectos en los que las contradicciones del pensamiento de Marinetti encuentra menos escapatoria, ya que su ideología nacionalista chocaba frontalmente con su idea de libertad. Sus ideas acerca de la libertad absoluta del hombre, de su desvinculación con el pasado y de las identidades que este arrastra, y en contra de la inmortalidad de las ideas y del arte, resultan difícilmente reconciliables con el extremo compromiso patriótico que requería el nacionalismo que él defendía. Aunque Marinetti trató de aunar ambos conceptos, en el momento de elegir, situó por encima de la libertad a la nación, como deja claro en varias ocasiones, sobre todo una vez comenzada la guerra ${ }^{3.15}$.

Para Marinetti, como para el resto de nacionalistas del momento, la nación era mucho más que un territorio geográfico en el que se habían desarrollado unas costumbres y una cultura. La nación era un territorio a la vez físico y espiritual en el que proyectar todo tipo de aspiraciones e ideales. Era esa idea-territorio en la que concebir esas imágenes románticas de aventura, heroísmo y escapismo de la trivial realidad (Busino, 1981), y además uno de los pocos símbolos seguros a invocar en medio de un contexto de constantes incertidumbres y de grandes cambios de toda índole que hacían dudar de todo aquello que hasta el momento había sido innegable. La nación se convirtió así en el recurso más utilizado al que recurrir para despertar y aludir a la masculinidad, la vitalidad y la fortaleza, en una época en la que estos valores se veían cuestionados. Así, Marinetti proclama: "Toda la libertad y todos los progresos pero en el círculo ideal de una Nación siempre más futurista. ¡Toda la libertad salvo aquella de ser cobardes!"’.16. Si el nacionalismo no hacía ninguna distinción práctica entre la política y sus prácticas y la cultura y las artes (Mosse, 1988), Marinetti desde luego mucho menos, y para él Italia era un concepto estético, artístico, político y siempre futurista.

El artista futurista debía entonces entender lo que implicaba la nación para el progreso de la modernidad, por lo que debía comportarse como un héroe. Como se ha visto, el heroísmo se constituyó así como ideal al que todo hombre debía aspirar, y este concepto tenía un sentido cada vez más político (y por supuesto nacionalista), que se alejaba del de Baudelaire, y defendía, con su tono habitual, la necesidad de un heroísmo cotidiano, que implicaba el amor al peligro, la violencia rehabilitada como argumento decisivo, la religión de la velocidad o la llegada de los jóvenes al poder contra el espíritu parlamentario, burocrático, académico y pesimista. ${ }^{3.17}$ 
La idealización de la guerra iba de la mano con esta mentalidad nacionalista. Era también una amalgama de pensamiento romántico, que idealizaba el valor y la lucha por unos ideales, junto con el culto al progreso y al engrandecimiento de las naciones, en el que la guerra era una herramienta imprescindible; y a todo esto se añadía la idolatría a la fuerza y a la masculinidad. La guerra era planteaba como un elemento natural de la modernidad, y los futuristas hicieron de ella una parte fundamental de su programa artístico-vital.

Aunque su evocación de la guerra se hará cada vez más fuerte a partir de 1914, cuando el conflicto se convierta en el centro de los debates de los intelectuales italianos (Dogliani, 2013), ya desde su primer manifiesto, en 1909, Marinetti defiende la guerra como "única higiene del mundo", y siempre la vinculará con el arte, explicando que el arte no puede ser otra cosa que violencia, crueldad e injusticia. ${ }^{3.18}$

El tema de la guerra en el futurismo ha sido una cuestión de amplio debate, ya que los límites entre lo metafórico y lo literal no son muy claros. Para uno de los mayores estudiosos del fascismo italiano, el ya citado Emilio Gentile, la invocación de la guerra iba más allá del sentido estético, y los escritos de Marinetti parecen confirmar esta idea: "La exaltación de la guerra fue un ingrediente esencial del entusiasmo de los futuristas por la modernidad: y la guerra, para los futuristas, no era una metáfora retórica, sino el combate armado entre los pueblos" (Gentile, 1988, p. 114. Traducción propia).

De esta forma, la guerra es vista por Marinetti como algo más que una evocación de la acción. Consideraba, y esto es fundamental, que formaba parte de la vida y del arte y que por ello debía tener una presencia real en estas. Su apoyo a la intervención de Italia en la guerra fue contundente y enérgico, sin ambages, y su ideología belicista no disminuyó ni durante esta ni después, y consideró guerra como el más bello poema futurista aparecido hasta el momento. ${ }^{3.19}$ Para Marinetti, la guerra significaba acción verdadera, y soñaba con introducir la guerra en el arte como sinónimo de introducir realmente la vida en el arte, a través del combate contra lo viejo y lo pasado. "La guerra era fiesta ritual de regeneración colectiva que purificaba de las incrustaciones del hombre viejo y preparaba el nacimiento del hombre nuevo. Iniciaba una nueva vida, toda proyectada hacia el futuro, en una condición de entusiasmo catártico y creativo para los italianos combatientes". (Gentile, 1988, p. 119. Traducción propia.)

En sus manifiestos, Marinetti defiende no solo la exaltación de la guerra por parte del artista futurista, sino también la participación real de estos en la contienda bélica, y expresa que "los artistas, finalmente vivos y ya no sobre las cimas despreciables del esteticismo, quieren colaborar como operarios y soldados al progreso mundial, y realizar el heroísmo cotidiano que predica el futurismo". ${ }^{3.20}$ Para Marinetti, la lucha y la participación en la guerra forma parte de esa implicación activa y de esa acción que el artista futurista debe realizar como parte de su rol social.

Sin embargo, y a pesar de su empeño en la participación activa en la sociedad, la postura de decidida presencia política, a diferencia de su doctrina belicista y nacionalista, no fue constante. Su fuerte ideología nacionalista siempre estuvo presente en todos sus textos, en los que el genio, la nación y la raza italianos siempre fueron grandes protagonistas de sus manifiestos, manteniendo una actitud de nacionalismo modernista (Gentile, 1988). No lo estuvo así la activa y real práctica política, en el sentido más pragmático de la palabra ${ }^{4}$. 
En cualquier caso, sus ideas nacionalistas y su forma de participar en política hicieron que se vinculara al fascismo desde sus comienzos. A pesar de las grandes sintonías ideológicas que Marinetti tenía con el fascismo, no fueron estas tan relevantes para este último como el estilo de comportamiento, como explica Emilio Gentile. Para este autor, el estilo de comportamiento fascista tuvo como referente la ideología futurista porque "era principalmente un modo de vivir que se formaba y se expresaba a través de la acción. El misticismo de la acción y el estilo futurista fueron corroborados por la experiencia de la guerra, a partir de las manifestaciones intervencionistas y principalmente a través de la simbiosis del futurismo y el arditismo" (Gentile, 1988. p. 135. Traducción propia).

Así, la asociación entre estética y política, proveniente de ese pensamiento que aunaba en un todo lo filosófico, artístico y político (De Maria, 1988) proporcionó al fascismo algunas de las herramientas más útiles para captar atención y apoyos en la época de las grandes masas urbanas. Junto con D'Annunzio, Marinetti creó un aparataje artístico-propagandístico, basado en grandes espectáculos performativos (Gómez Llanos, 2010) y una actitud desafiante y agresiva, pero también festiva (Salaris, 2002), que Mussolini supo adaptar a la práctica política de masas del fascismo.

El estilo fascista de comportamiento fue un instrumento de gran trascendencia para el propio desarrollo de la política de los años 20 y 30, que quedó marcada, entre otras cosas, precisamente por esas prácticas estéticas. La sociedad de masas, en la que los medios de comunicación cobraban cada día mayor importancia, posibilitó que el arte y la política convivieran de esta manera, entre otras, a principios del siglo XX, marcando una de las tendencias de mayor importancia de la época moderna.

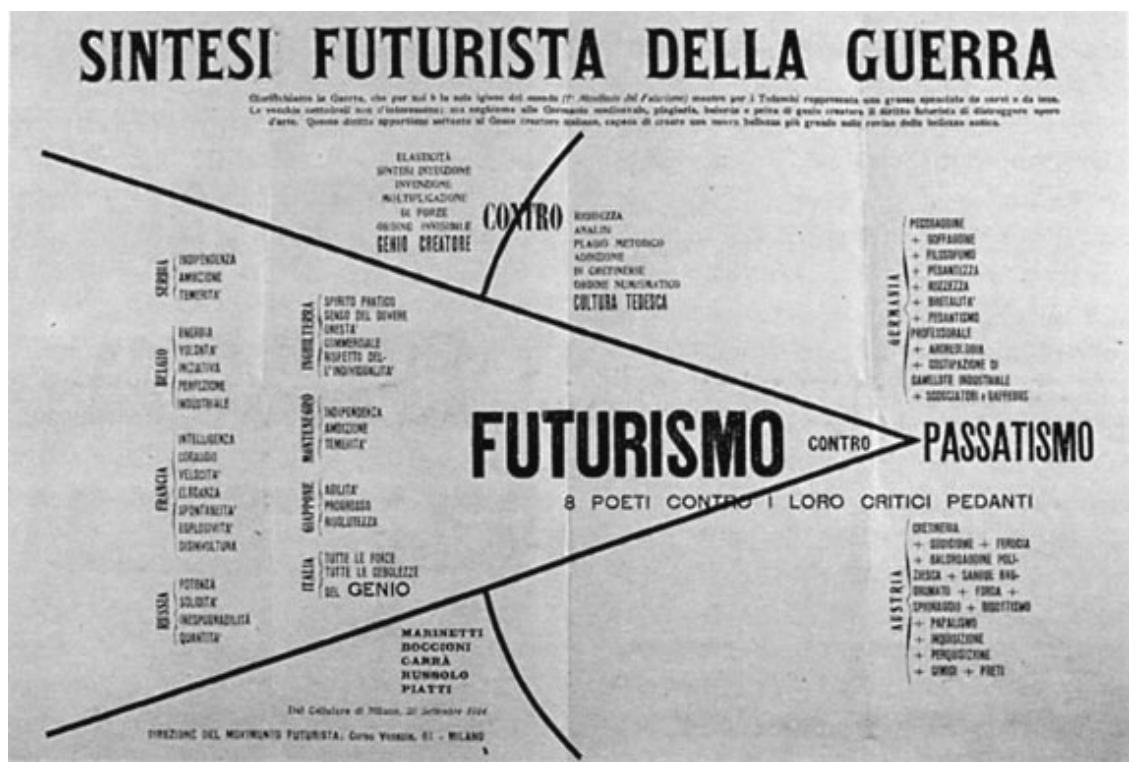

Figura 6. Marinetti, Boccioni, Carrà, Russolo, Piatti, Sintesi futurista della guerra, volantino della Direzione del Movimento futurista, 20 settembre 1914. Fuente: www.internetculturale.it 


\section{Conclusiones}

Marinetti imaginó un nuevo modelo de artista que fuera tanto representante como líder de la modernidad. Para ello, otorgó a este la más alta libertad creadora, el genio más elevado y la capacidad para crear un nuevo mundo sin influencia del pasado. Aspiraba a generar un nuevo agente social, con gran carisma y habilidad para captar atención, que introdujera de manera fulminante a la Italia de principios de siglo en la más plena modernidad. El progreso, el nacionalismo, la guerra, la máquina o la velocidad eran algunos de los elementos de esa modernidad que el artista debía incorporar a su obra, para hacer de esta su activador y lograr hacerla realidad.

Con el objetivo de abarcar todo tipo de expresión artística con su movimiento y dentro de su aspiración a la globalidad, Marinetti logró captar e incorporar a numerosos artistas jóvenes de muy diversas áreas a las filas de futurismo. De esta forma, consiguió crecer y ganar gran repercusión en la vida cultural y más tarde política de Italia, abarcando el futurismo la poesía, el teatro, la pintura, la escultura, la arquitectura, la música o el diseño, y logrando convertirse en un verdadero movimiento global, artístico y extra artístico.

Insertó al artista en la vida social y activa del momento, buscando una acción y una lucha constante contra lo establecido, aspirando a ese heroísmo cotidiano heredado del Romanticismo e inflamado por su nacionalismo desbordante. A raíz de estas vías, Marinetti se vinculó de forma entusiasta con el fascismo cuando este surgió, al ver en este la lucha y la acción que Italia necesitaba para despojarse de las lastras del pasado, $y$, a pesar de la controvertida relación que Marinetti tuvo con Mussolini, finalmente el futurismo se fue convirtiendo en la vanguardia artística representativa del nuevo régimen.

Así, Marinetti, que había defendido tanto la extrema libertad del artista, y que había rechazado un papel para este que no fuera el de su propia autodeterminación, acabó colocando al artista futurista bajo el fascismo, y proporcionó a este (primero de forma voluntaria y activa, después más bien pasiva) un exitoso aparataje propagandístico perfectamente adaptado a las grandes masas y de gran eficacia para su movilización y captación a través de elementos estéticos. Entre estos, ocuparía un lugar primordial, como se ha visto, la guerra, que Marinetti entendió como culminación de la experiencia estética, como obra artística absoluta, pero no solo como idea sino también como realidad. "Tal es la estetización de la política del fascismo", dice Walter Benjamin (2003, p. 62), -que contrapone negativamente a la politización del arte del comunismo-. Y sin embargo, la estetización absoluta de Marinetti proveniente del decadentismo no sobrevive a la politización del arte que también acaba haciendo el fascismo italiano sobre el futurismo. Aunque estos dos conceptos formaban parte de la misma moneda (Perloff, 2009), en la gestación del futurismo, Marinetti no contempla esa politización del arte, ya que habría suprimido la libertad suprema de esta, y, sin embargo, va conduciendo su movimiento precisamente hacia ello. El que fuera en origen el máximo estandarte de artista libre acabó siendo un mero adorno de cierta extravagancia del régimen fascista en los años posteriores.

Y sin embargo, el modelo martinettiano de artista libre de vanguardias, creador de un arte globalizante y de su consiguiente praxis artística y extra artística, superó y fue más allá de la coyuntura de su época, y se convirtió en uno de los arquetipos de 
artista con más fuerza de la cultura contemporánea. Un modelo que continúa vigente hoy día y que forma parte del universo artístico moderno.

\section{Referencias}

Aguirre, J. M. (1996). El tema del individuo superior en la literatura decimonónica. Espéculo. Revista de estudios literarios. 3. Universidad Complutense de Madrid.

Baudelaire, C. (1999). Salones y otros escritos sobre arte. Madrid: La Balsa de la Medusa.

-----(2007). El pintor de la vida moderna. Murcia: Colegio Oficial de Aparejadores y Arquitectos Técnicos de la región de Murcia.

Bénichou, P. (1981). La coronación del escritor: ensayo sobre el advenimiento de un poder espiritual laico en la Francia moderna. México: Fondo de Cultura Económica.

Benjamin, W. (2003). La obra de arte en la época de su reproductibilidad técnica. México: Itaca.

Blanning, T. (2012). The Romantic Revolution. New York: Phoenix.

Blom, P. (2010). Años de vértigo. Cultura y cambio en Occidente, 1900-1914. Barcelona: Anagrama.

Bürger, P. (1997). Teoría de la vanguardia. Barcelona: Península.

Busino, G. (1981). Il nazionalismo italiano e il nacionalismo europeo. En AA.VV. La cultura italiana tra ' 800 e '900 e le origini del nazionalismo (pp. 47-67). Firenze: Leo Olschki Editore.

Calvo Serraller, F. (2013). La invención del arte español. Barcelona: Galaxia Gutenberg.

Dogliani, P. (2013). Los intelectuales italianos en la Gran Guerra: intervencionismo, patriotismo, neutralismo (1914-1918). Ayer, 91, pp. 93-120.

Fusi Aizpurúa, J. P. 2003. La patria lejana. El nacionalismo en el siglo XX. Madrid: Taurus.

-----(2013). Breve historia del mundo contemporáneo. Desde 1776 hasta hoy. Barcelona: Galaxia Gutenberg.

Gentile, E. (1988). Il futurismo e la politica. Dal nazionalismo modernista al fascismo (1909-1920). En De Felice, Renzo (Ed.), Futurismo, cultura e politica (pp. 105160). Torino: Edizioni Fondazione Giovanni Agnelli.

Gómez L. (2008). La dramaturgia futurista de Filippo Tommaso Marinetti: el discurso artístico de la modernidad. Vigo: Academia del Hispanismo.

----- (2010). Comunicación de masas y Futurismo: la conformación del público y la escena mediática. Espéculo. Revista de estudios literarios, 45. Universidad Complutense de Madrid.

Guerri, G. B. (1988). Bottai: da intellettuale futurista a leader fascista. En De Felice, Renzo (Ed.), Futurismo, cultura e politica. (pp. 221-246). Torino: Edizioni Fondazione Giovanni Agnelli.

Herrero, J. (2012). Introducción: «À Rebours» («A contrapelo») y la crisis de valores culturales y artísticos de fin de siglo, y «À Rebours» y el movimiento decadente. En Huysmans, Joris- Karl, A contrapelo (pp. 9-23). Madrid: Cátedra. 
De Maria, L. (1988). Il ruolo di Marinetti nella costruzione del futurismo. En De Felice, Renzo (Ed.), Futurismo, cultura e politica (pp. 33-48). Torino: Edizioni Fondazione Giovanni Agnelli.

Marinetti, F. T. (1968). Teoria e invenzione futurista. A cura di Luciano De Maria. Milano: Mondadori.

De Micheli, M. (1993). Las vanguardias artísticas del siglo XX. Madrid: Alianza.

Mosse, G. L. (1988). Futurismo e cultura politica in Europa: una prospettiva globale. En De Felice, Renzo (Ed.), Futurismo, cultura e politica (pp. 13-32). Torino: Edizioni Fondazione Giovanni Agnelli.

Murger, H. (2007). Escenas de la vida bohemia. Madrid: Alba Editorial.

Perloff, M. (2009). El momento futurista. Valencia: Universidad Politécnica de Valencia.

Poggioli, R. (1964). Teoría del arte de vanguardia. Madrid: Revista de Occidente.

Salaris, C. (2002). Alla festa della revoluzione. Artisti e libertari con D'Annunzio a Fiume. Bologna: Il Mulino.

Wittkower, R. (2004). Nacidos bajo el signo de Saturno. Genio y temperamento de los artistas desde la Antigüedad hasta la Revolución Francesa. Madrid: Cátedra.

\section{Notas}

1. 1. Como explica Philip Blom para el caso de Maurice Barrès, que también tuvo un pasado decadente para luego arremeter contra ese comportamiento (y ser uno de los mayores nacionalistas y ultraderechistas de Francia), Marinetti también fue uno de esos ideólogos que, "como muchos conversos, lo que más detestaba era su propio pasado, y en particular la decadencia que una vez había predicado" (Blom, 2010, p. 33).

2. 2. Después de sus primeras obras, los poemas Conquête des etoiles (1902) y Destruction (1904) y la tragedia satírica Le Roi Bombance (1905)66, Marinetti escribe la novela Mafarka el futurista, publicada en 1909, justo después de su primer manifiesto futurista, en la que también se observan algunos de los elementos fundamentales del pensamiento futurista marinetiano, principalmente el culto a la máquina. Es precisamente aquí donde De Micheli más subraya cómo permanece el carácter decadente en la primera prosa futurista de Marinetti. Para él, en esta novela, Marinetti realiza lo que denomina como la "motorización del decadentismo"67, tomando elementos decadentes como el exotismo y el concepto del superhombre tan en boga en aquel momento, a los que incorpora el ideal de la máquina como ingrediente fundamental de lo moderno. Mafarka el futurista tendrá un gran peso en la configuración de la ideología e imaginería futurista y resulta un importante puente en el que se aprecia esa conexión entre el decadentismo y el futurismo. Para De Micheli, "Marinetti, después de la fuga al exotismo, regresa al orden de la burguesía lombarda pilotando el pájaro mecánico de Mafarka. Su «estética de la máquina» se hará en gran parte con las alas de este decadente ingenio volador; sus gritos y sus frases patrioteras e intervencionistas estarán compuestas con los períodos de su novela africana" (De Micheli, 1993, p. 63).

3. 3. A partir de aquí se hacen referencia a distintos textos de manifiestos de Marinetti (solo o con otros artistas) a través de notas, para poder especificar la edición y año de publicación de cada uno de ellos. La traducción de los textos de los manifiestos es propia. 
3.1. Filippo Tomasso Marinetti, "Fondazione e Manifesto del Futurismo", publicado el 20 de febrero de 1909, como editorial, en francés en el periódico Figaro, fue republicado en italiano en: Poesía, V, n. 1-2, febbraio marzo 1909, Edizioni di «Poesia», Milano, 1909. En Marinetti, Filippo Tommaso. (1968). Teoria e invenzione futurista. A cura di Luciano De Maria. Milano: Mondadori (A partir de ahora T.I.F.M). p. 10.

3.2. Filippo Tomasso Marinetti, "Manifesto tecnico della letteratura futurista", publicado por primera vez en 1912 como introducción a la antología "I poeti futuristi", Edizioni futuriste di Poesia, Milano, 1912. En T.I.F.M., p. 47.

3.3. Filippo Tomasso Marinetti, "Noi rinneghiamo i nostri maestri simbolisti ultimi amanti della luna”, en Guerra sola igiene del mondo, Edizione futuriste di Poesia, Milano, 1915. En T.I.F.M., p. 260.

3.4. Nota 3.2.

3.5. Filippo Tomasso Marinetti, "Prime battaglie futuriste" en Guerra sola igiene del mondo, Edizione futuriste di Poesia, Milano, 1915. En T.I.F.M., p. 201.

3.6. Filippo Tomasso Marinetti, "Contro i professori”, en Guerra sola igiene del mondo, Edizione futuriste di Poesia, Milano, 1915. En T.I.F.M., p. 265.

3.7. Filippo Tomasso Marinetti, Emilio Settimelli, Bruno Corra, "Il teatro futurista sintetico", en AA vari, Teatro futurista sintetico, Istituto Editoriale Italiano, Milano, 1915. En T.I.F.M., p. 103.

3.8. Nota 3.7

3.9. Filippo Tomasso Marinetti, Bruno Corra, Emilio Settimelli, Arnaldo Ginna, Giacomo Balla, Remo Chiti, "La cinematografia futurista", en L'Italia Futurista, I, no10, 15 novembre 1916, en T.I.F.M., p. 118.

3.10. Nota 3.6

3.11. Filippo Tomasso Marinetti, "Prime battaglie futuriste" en Guerra sola igiene del mondo, Edizione futuriste di Poesia, Milano, 1915. En T.I.F.M., p. 201.

3.12. Nota 3.6

3.13. Filippo Tommaso Marinetti, "Il cittadino eroico, l'abolizione delle polizie e le scuole di coraggio", en en Democrazia Futurista (Dinamismo Politico), Facchi Editore, Milano, 1919, en T.I.F.M., p. 388.

3.14. Filippo Tomasso Marinetti, "Nascita di un'estetica futurista" en en Guerra sola igiene del mondo, Edizione futuriste di Poesia, Milano, 1915. En T.I.F.M., p. 269

3.15. Filippo Tommaso Marinetti, "Discorso del Teatro Verdi" [pronunciato in Firenze il 12 dicembre 1913 e pubblicato dal giornale «Lacerba»], en Futurismo e Fascismo, Franco Campitelli Editore, Foligno, 1924. En T.I.F.M., p. 435.

3.16. Nota 3.15

3.17. Marinetti, Filippo Tommaso. Futurismo e fascismo. Campitelli: Foligno. 1924. p. 16. Citado en Guerri, Giordano Bruno. "Bottai: da intellettuale futurista a leader fascista" en De Felice, Renzo (ed.) Futurismo, cultura e politica. Torino: Edizioni Fondazione Giovanni Agnelli. 1988. p. 229.

3.18. Nota 3.1. P. 13

3.19. Filippo Tommaso Marinetti, "In quest'anno futurista”, en Guerra sola igiene del mondo, Edizione futuriste di Poesia, Milano, 1915. En T.I.F.M., p. 286.

3.20. Nota 3.19. P. 284. 
4. Marinetti, desde su activa presencia pública tras la publicación del primer manifiesto, fue aumentando su participación política, muy activa durante la guerra los años siguientes, hasta llegar a su máximo apogeo en 1918, cuando funda el Partito Futurista Italiano, y a lo largo de 1919, durante la empresa dannunziana en Fiume. Ya antes los futuristas habían entrado en el terreno político activo a través de los Fasci di combattimento (con sus propios Fasci Futuristi di combattimento en varias ciudades italianas), de los que se formaría más tarde el Partido Fascista de Mussolini, pero tras la fundación del Partido Futurista hacen una entrada más oficial. A pesar de las sintonías con el fascismo de Mussolini, Marinetti no se entendió realmente con él y, al poco tiempo de la formación del partido, se desvinculó totalmente de la política, llegando a aborrecerla119. Fue tras el Congreso Fascista de mayo de 1920 en Milán cuando se hace oficial la salida de Marinetti y de otros futuristas de la política activa fascista, aunque las disonancias venían de antes, ya que Marinetti consideraba que el rumbo que estaba tomando Mussolini era muy conservador, mientras que él continuaba defendiendo la ideología radical nacionalista antimonárquica y anticatólica. Apartado de la política durante unos años, Marinetti volvió a las filas oficiales del fascismo en 1924, con intención de relanzar el futurismo, pero mantuvo una presencia limitada e, igual que D'Annunzio, la otra gran figura artística y literaria del nacionalismo italiano, pasó a ser una suerte de ornamento del régimen fascista. 